50

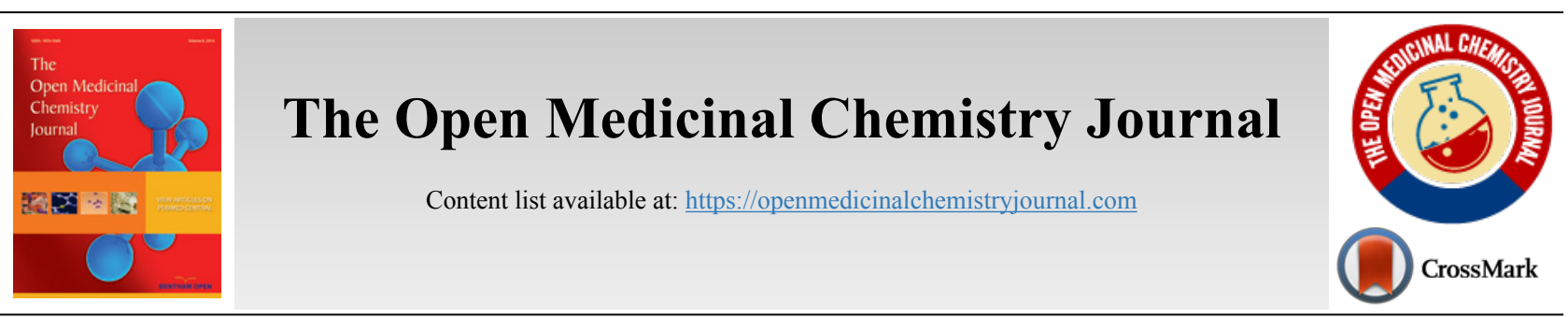

RESEARCH ARTICLE

\title{
In vivo Anti-Plasmodium Activity and Toxicity of Afzelia bipindensis and Senna Siamea Extracts: A Murine Model
}

\author{
Mbah N. L. Javeres ${ }^{1,2, *}$, Syed M. Nurulain ${ }^{2}$, Oumarou G. Hamadama ${ }^{1,3}$, Haris J. Bello ${ }^{2}$ and Anas Muazu ${ }^{2}$ \\ ${ }^{I}$ Institute of Medical Research and Medical Plants Studies, Ministry of Scientific research, Yaounde, Cameroon \\ ${ }^{2}$ Department of Biosciences, COMSATS University, Islamabad, Pakistan \\ ${ }^{3}$ Department of Microbiology, University of Yaounde 1, Yaounde, Cameroon
}

\begin{abstract}
:
Background:

Malaria, a parasitosis affecting man, remains a public health problem in developing countries where morbidity and mortality are very high. Afzelia bipindensis and Senna siamea are two plants used in the treatment of malaria in different African countries including Cameroon.

Objective:

The aim of the present study was to evaluate the antiplasmodial activity of hydroethanolic leaves extracts of Afzelia bipindensis and Senna siamea, from Northern Cameron using Plasmodium berghei and to investigate the acute and sub-acute toxicity of leaves extracts in a rodent model.

Methods:

The four days Peter's suppressive test was used to evaluate the antiplasmodial activity and the OCDE 423 and 412 guidelines were applied to evaluate acute and sub-acute toxicity. Biochemical tests related to hepatic, cardiac and renal toxicity were also assessed.

Results:

The leaves' extracts of Afzelia bipindensis at doses 180,360, $720 \mathrm{mg} / \mathrm{kg}$ and Senna siamea at doses of 100, 200, 400 mg/kg have shown significant antiplasmodial activity $(\mathrm{P})$ with parasite reduction $\approx 50 \%$. No mortality of rats was observed at the tested doses. The biochemical analysis did not reveal any statistically significant difference when compared with control. However, ALT was statistically increased at a higher dose ( $720 \mathrm{mg} / \mathrm{kg}$ ) of Afzelia bipindensis leaves extract. On the other hand, there was a significant decrease in triglycerides at $360 \mathrm{mg} / \mathrm{kg}$ and $720 \mathrm{mg} / \mathrm{kg}$

Conclusion:

It is concluded that daily consumption of leaves extract of Afzelia bipindensis and Senna siamea are without significant risks to human health, favoring the use of these products in the treatment of malaria.
\end{abstract}

Keywords: Malaria, Afzelia bipindensis, Senna siamea, Extracts, Toxicity, Triglycerides.

Article History

Received: March 30, 2019

Revised: June 10, 2019

Accepted: June 12, 2019

\section{INTRODUCTION}

Malaria is a parasitic disease widely distributed around the world. This parasitosis is a handicap to the development of many countries. Every year, about 250 million people become sick and nearly 1 million die [1]. In 2000, malaria transmission was active in 106 countries and territories with 262 million cases and 839,000 fatalities. In 2016, malaria was active in 95

* Address corresponding to this author at the Institute of Medical Research and Medical Plants Studies, Ministry of Scientific research Yaoundé, Cameroon; Tel: +237 699011394/+92 3115002198; E-mail: mbahj1@yahoo.fr countries with 214 million cases worldwide and 438,000 deaths, among which 188 million cases were recorded in Africa with 395,000 deaths. Sub-Saharan Africa is the continent most affected by this epidemic with about $88 \%$ of cases and deaths worldwide [2]. In Cameroon, malaria is very dangerous and remains one of the main causes of morbidity and mortality. In 2016, the mortality rate caused by malaria was still high with nearly 4,000 registered deaths and the most affected areas were the Far North and North with $40 \%$ of deaths [3]. The main epidemiological types of malaria in Africa are found in Cameroon and today the fight against this epidemic remains 
oriented towards the vector agent, the curative and prophylactic treatment. In order to face such a problem in the world, control strategies have been developed such as awareness of the population, the vector control, and the prevention of malaria in pregnant women and the early and effective treatment of cases [4]. WHO has reported a dramatic decline in malaria over the last 15 years. Despite this remarkable progress, much remains to be done as malaria continued to decimate African populations with considerable loss of human life. The Global Technical Strategy for Malaria 2016-2030 has set ambitious and achievable targets for 2030, including a reduction of at least $90 \%$ in malaria incidence and mortality. The chemotherapeutic treatment of malaria has evolved over the past 10 years as a result of the spread of multidrug-resistant strains of Plasmodium falciparum, and WHO has now promoted combination therapies based on artemisinin and or its derivatives (ACT) as Reference medicine for the management of uncomplicated malaria in order to reduce the risk of resistance [5] However, some signs of resistance to artemisinin have recently been detected in Asia, posing a huge threat to the control of malaria Disease [6]. The discovery of new antimalarial drugs is urgently needed, and plants were believed to play an important role in this new challenge, which is why current strategies are guiding research into the research and development of new antimalarial drugs. The plants of the traditional pharmacopoeia constitute an interesting research material because the main antimalarial drug currently used in therapeutics (quinine and artemisinin) remain predominantly of plant origin. Although, uncontrolled use of these plants may lead to other health complications [7 - 9]. According to WHO, $80 \%$ of rural people living in developing countries depend on traditional medicine for their primary health care requirement. The art of healing by plants has been known and practiced in Africa for a very long time because it exploits knowledge and transmitted orally from generation to generation to certain categories of initiated individuals that are the traditional healers and herbalists. Medicinal plants and knowledge about medicinal plants and traditional medicines are an important heritage of the African continent. Moreover, for the vast majority of the world's population, traditional medicine is the only treatment opportunity, while for many others, it is a choice motivated by a range of reasons that vary from place to place, from culture to person.

Our objective was to evaluate the antiplasmodial activity of hydroethanolic leaves extracts of Afzelia bipindensis and of Senna siamea harvested in Northern Cameroon. The outcome of the study provide an effective alternative for the treatment of malaria.

\section{MATERIALS AND METHODS}

\subsection{Leaves of $A$. bipindendis and $S$. siamea}

A. bipindensis and S. siamea are plants that are cultivated in Africa. A. bipindensis is a tree whereas the $S$. siamea is a legume that's routinely used as food in Africa. The leaves of $A$. bipindensis Fig. (1A) and $S$. siamea Fig. (1B) were harvested during the month of December 2017 in the city of Maroua, Cameroon. After harvest, these leaves were dried for one week in the dark at room temperature, then crushed in mortars and sieved to obtain a powder with good particle size.

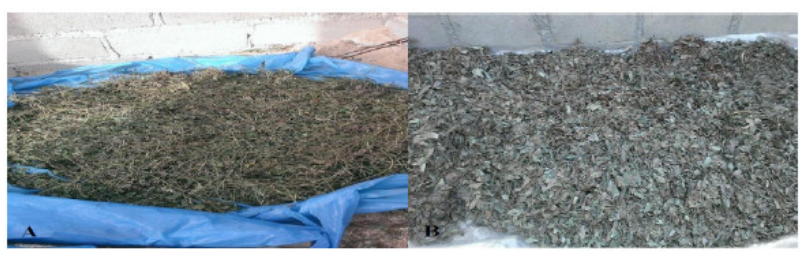

Fig. (1). Dry leaves of Afzelia bipindensis (A) and Senna siamea (B).

\subsection{Extract Preparation}

Extracts were prepared according to Zirihi et al. [10]. The leaves of Afzelia bipindensis and Senna siamea were kept in a dry area, away from the sun. They were separately crushed in a grinding mill. Hundred grams of each powder obtained was introduced in $1.5 \mathrm{~L}$ of ethanol $70 \%$. Each mixture was homogenised for several minutes using a clean wooden stick and left to stand for $24 \mathrm{~h}$. Then the gross macerates obtained were separated from the residual powder by pressing, then filtering through a Whatman No. 1 filter paper. The filtrates obtained were concentrated in a rotavapor then evaporated in an oven for 2 days at $40^{\circ} \mathrm{C}$. Pasty and darkish hydroethanolic extracts for Senna siamea and greenish for Afzelia bipindensis were obtained.

\subsection{Phytochemical Analysis and Preparation of Test Solutions}

The phytochemical analysis was carried as previously described by Harborne [11]. Based on the color intensity of the solutions, five cutoffs; absence $(-)$, trace $(+/-)$, low $(+)$, abundant $(++)$ and very abundant $(+++)$ were used to define the intensity of each metabolite in the plants.

The extract $(100 \mathrm{~g})$ was dissolved in $0.5 \mathrm{~L}$ distilled water, and the mixture was homogenized by agitation (5-10 $\mathrm{min}$ ) using a magnetic stirrer. The solutions obtained were kept in a closed plastic jar and stored at $4^{\circ} \mathrm{C}$ after every administration session to animals. The volumes of the solutions administered to animals were calculated using the following formula.

$$
V=\frac{D \times P}{C}
$$

Where; $\mathrm{V}=$ volume of solution administered $(\mathrm{mL}) ; \mathrm{D}=$ dose $(\mathrm{mg} / \mathrm{kg}) ; \mathrm{P}=$ animals weight $(\mathrm{Kg}) ; \mathrm{C}=$ concentration of the solution to be administered $(\mathrm{mg} / \mathrm{mL})$.

\subsection{In vivo Evaluation of the Antiplasmodial Activity of Afzelia bipindensis and Senna siamea Extracts in BALBc Mice}

The antiplasmodial activity was evaluated according to the method described by Trager and Jensen 1976 [12]. The experimental mice $(\mathrm{n}=30)$ were inoculated by intraperitoneal injection at day 0 , with $0.2 \mathrm{ml}$ of infected blood containing $1 \mathrm{x}$ $10^{7}$ Plasmodium berghei NK65 strain in blood. Three hours after inoculation of the parasite, the animals were divided into 5 groups of 6 animals $\left(\mathrm{G}_{1}-\mathrm{G}_{5}\right)$. The first three groups $\left(\mathrm{G}_{1}, \mathrm{G}_{2}\right.$, and $\mathrm{G}_{3}$ ) of BALBc mice received the hydroethanolic extracts daily for four days by oral gavage using an oesophageal 
intubation tube. Doses of 180, 360 and $720 \mathrm{mg} / \mathrm{kg}$ for Afzelia bipindensis and 100, 200, and $400 \mathrm{mg} / \mathrm{kg}$ for Senna siamea were chosen for the treatment. The fourth group (G4) of mice received $200 \mu \mathrm{l}$ of water and the last group (G5) received quinine $(10 \mathrm{mg} / \mathrm{kg})$. Blood smears were prepared on day 5 by collecting a drop of blood from the animals' tails on a glass slide, then fixed with methanol and stained with giemsa staining procedure. The parasite count was obtained by using the modified Zucker and Campbell [13] formula:

$$
\% \text { Parasitemia }=\frac{\text { Number of infected red blood cells }}{\text { Total number of blood cells examined red }} \times 100
$$

The efficiency of the treatment for each extract was evaluated by calculating the mean percentage of reduction of parasite according to the equation:

$$
\% \text { reduction }=\frac{C-T}{C} \times 100
$$

Where; $\mathrm{C}=$ Mean parasitemia percentage in the negative control group

$\mathrm{T}=$ mean parasitemia percentage in the treated group

\subsection{Evaluation of Acute Toxicity}

Acute toxicity of Afzelia bipindensis and Senna siamea extracts were evaluated in albino rats according to the OCDE no. 423 [14] guidelines for trials using chemical substances adopted on the 17 of December 2001. Four geometrically increasing doses of $2000 \mathrm{mg} / \mathrm{kg}, 3000 \mathrm{mg} / \mathrm{kg}, 4000 \mathrm{mg} / \mathrm{kg}$, and $5000 \mathrm{mg} / \mathrm{kg}$ of the substance were administered by oesophageal intubation. The substance is tested in a sequential manner in which three same-sex animals were used at each stage. The animals were observed within 48 hours after administration of a dose, if all the animals survived, a higher dose was administered until the dose led to mortality.

\subsection{Evaluation of Sub-acute Toxicity}

Sub-acute toxicity of Afzelia bipindensis and Senna siamea was evaluated in rats according to the OCDE no. 412 [15] guidelines for trials using chemical products adopted on the $7^{\text {th }}$ September 2009. Each group of rats received doses of 180, 360 or $720 \mathrm{mg} / \mathrm{kg}$ for Afzelia bipindensis and 100, 200 or 400 $\mathrm{mg} / \mathrm{kg}$ orally for Senna siamea, using an intubation tube for 28 days. The control group received an equal volume of distilled water. The experimental albino rats were observed every day during the 28 days of treatment and weighed every week until the $28^{\text {th }}$ day. Experimental animals were observed everyday morning and evening to see symptoms of morbidity and mortality. From the fourth week of exposition, the sensorial reactiveness to auditory and proprioceptive stimuli, prehension force and motor activity were also evaluated every day.

Weekly body weight variations were noted. The formula used for the calculation of the variation in body weight was:

$$
\mathrm{GP}=\frac{\mathrm{Pn}-\mathrm{Pn}-1}{\mathrm{Pn}-1} \times 100
$$

Where, GP = weight gain (\%)

$\mathrm{P}_{\mathrm{n}}=\mathrm{n}^{\text {th }}$ measure of body weight

$\mathrm{P}_{\mathrm{n}-1}=(\mathrm{n}-1)^{\text {th }}$ measure of body weight

\subsection{Macroscopic Analyses of Organs and Biochemical Analysis of Blood}

The animals were made to fast during the night preceding blood collection. They were then anesthetized using $0.5 \mathrm{~mL}$ of thiopental and blood samples were collected by cardiac puncture. The blood was collected in plain glass tubes for serum and centrifuged at $3000 \mathrm{rpm}$ for 5 minutes to obtain serum. The liver, the heart, the kidney, the spleen and the lung were collected, rinsed in saline solution $(0.9 \% \mathrm{NaCl})$, pressed on a filter paper and weighed using an electronic balance. The relative weight of each organ was evaluated using the following formula:

$$
\text { Relative weight of the organ }(\%)=\frac{\text { absolute weight of the organ }(g)}{\text { body weight of the animal }(g)} \times 100
$$

The serum obtained was used for biochemical measurements, carried out according to protocols provided in commercial kits (Biolab, Cat 150515 FRA). It includes Alanine Aminotransferase (ALT) and aspartate aminotransferase (AST). Assays were conducted for glucose, triglycerides, urea, creatinine (RECKON DIAGNOSTICS kit. Cat 100713 USA), total proteins and total cholesterol (BIOSYSTEMS kit). Hematological parameters were determined using an automated hematology analyzer (Hospitex Diagnostics Hema 18 Samsung 2000) and included blood count (red blood cells, white blood cells, hemoglobin, hematocrit, mean corpuscular hemoglobin, corpuscular hemoglobin concentration, and platelets).

\subsection{Statistical Analysis}

The data were processed by R software version 3.2.0 and Microsoft Excel version 2010. Statistical comparisons were made using one-way ANOVA and post ad hoc tests for specific comparisons. The significance of the differences between the treated and control groups was evaluated by Student's t-test, the differences were considered significant for $p<0.05$.

\section{RESULTS}

\subsection{Main Chemical Groups Highlighted in Extracts by Characterization Reactions}

\subsubsection{Antiplasmodial Activity}

Tables 2 and 3 show the effects of $A$. bipindensis and $S$. siamea extracts on the parasitemia of mice. Extracts of $A$. bipindensis at 180, 360 and $720 \mathrm{mg} / \mathrm{kg}$ and S. siamea at 100 , 200 and $400 \mathrm{mg} / \mathrm{kg}$ showed antiplasmodial activity greater than $50 \%$ in all BALB / c mice infected with Plasmodium berghei with a significant difference $(p<0.001)$.

\subsection{Effects of $A$. bipindensis and $S$. siamea Extracts on the Temperature of Parasitized Mice}

Figures show the effect of $A$. bipindensis Fig. (2) and $S$. siamea Fig. (3) extract on the temperature of parasitized mice. the quinine-treated mice promptly increase in body temperature, whereas the other treatments, including the water negative control, stay low. However, the differences observed are not statistically significant. 
Table 1. Chemical Groups Highlighted by Characterization Tests.

\begin{tabular}{|c|c|c|c|}
\hline \multirow[b]{2}{*}{$\begin{array}{c}\text { Extraction } \\
\text { Solvents }\end{array}$} & \multirow[b]{2}{*}{ Chemical Groups } & \multicolumn{2}{|c|}{ Plant Drugs } \\
\hline & & $\begin{array}{c}\text { Leaves of } \\
\text { Afzelia } \\
\text { bipindensis }\end{array}$ & $\begin{array}{l}\text { Leaves of } \\
\text { Senna } \\
\text { siamea }\end{array}$ \\
\hline \multirow{10}{*}{$\begin{array}{c}\text { Ethanol-Water } \\
(70: 30 \%)\end{array}$} & $\begin{array}{c}\text { Phenolic } \\
\text { compounds }\end{array}$ & +++ & +++ \\
\hline & Tannins & + & - \\
\hline & Catechin & + & + \\
\hline & alkaloids & $+/-$ & $+/-$ \\
\hline & Flavonoids & + & + \\
\hline & Glucosides & - & + \\
\hline & Steroids & + & - \\
\hline & Triterpenes & - & + \\
\hline & Saponosides & - & + \\
\hline & Coumarins & - & +++ \\
\hline
\end{tabular}

-: Absence, +/-: Traces, +: Low presence, ++: Abundant, +++: Very abundant

Table 2. Effects of hydroethanolic extracts of $\boldsymbol{A}$. bipindensis on parasitemia.

\begin{tabular}{|c|c|c|c|}
\hline \multirow{2}{*}{ Treatment } & $\begin{array}{c}\text { Dose } \mathbf{~ m g} \\
\mathbf{K g}\end{array}$ & Mean $\pm \mathbf{S D}$ & $\begin{array}{c}\text { Parasite Difference } \\
\mathbf{\%}\end{array}$ \\
\hline \multirow{3}{*}{ Extract } & 180 & $25.96 \pm 1.69 * * *$ & $53.01 \pm 2.39^{\mathrm{c}}$ \\
\cline { 2 - 4 } & 360 & $24.97 \pm 0.64 * * *$ & $54.81 \pm 1.91^{\mathrm{c}}$ \\
\cline { 2 - 4 } & 720 & $17.40 \pm 0.62 * * *$ & $68.50 \pm 1.49^{\mathrm{b}}$ \\
\hline Quinine & 10 & $0.21 \pm 0.14 * * *$ & $99.61 \pm 0.17^{\mathrm{a}}$ \\
\hline Distilled water & $200 \mu \mathrm{L}$ & $55.24 \pm 2.64$ & \\
\hline
\end{tabular}

*** Significant difference compared to the control group (distilled water) with student t-test $p<0.001 ; \mathrm{n}=6$. The comparison between groups treated was determined using ANOVA and Turkey HSD.

Table 3. Effects of hydroethanolic extracts of $S$. siamea on parasitemia.

\begin{tabular}{|c|c|c|c|}
\hline Treatment & $\begin{array}{c}\text { Dose mg } \\
\text { Kg }\end{array}$ & Mean \pm SD & Parasite Difference \% \\
\hline \multirow{3}{*}{ Extract } & 120 & $29.44 \pm 2.23 * * *$ & $46.70 \pm 4.20^{\mathrm{c}}$ \\
\cline { 2 - 4 } & 240 & $20.21 \pm 2.15^{* * *}$ & $63.41 \pm 2.97^{\mathrm{b}}$ \\
\cline { 2 - 4 } & 480 & $18.54 \pm 1.13^{* * *}$ & $66.43 \pm 2.26^{\mathrm{b}}$ \\
\hline Quinine & 10 & $0.21 \pm 0.14 * * *$ & $99.61 \pm 0.17^{\mathrm{a}}$ \\
\hline Distilled water & $200 \mu \mathrm{L}$ & $55.24 \pm 2.64$ & \\
\hline
\end{tabular}

$* * *$ Significant difference compared to the control group (distilled water) with student t-test $p<0.001 ; \mathrm{n}=6$. The comparison between groups treated was determined using ANOVA and Turkey HSD.

\subsection{Toxicity Observations and Effects of $A$. bipindensis and S. siamea Extracts on the Eeight}

The observations made on animals in acute tests. There was no change in the physical appearance and somatomotricity of the animals during the observation period. No manifestations of tremor, seizures, salivation, diarrhea, coma, or abnormal behaviours such as self-mutilation or walking backward were observed for both extracts. Lethargy was observed in all animals in the first 30 minutes after forcefeeding.

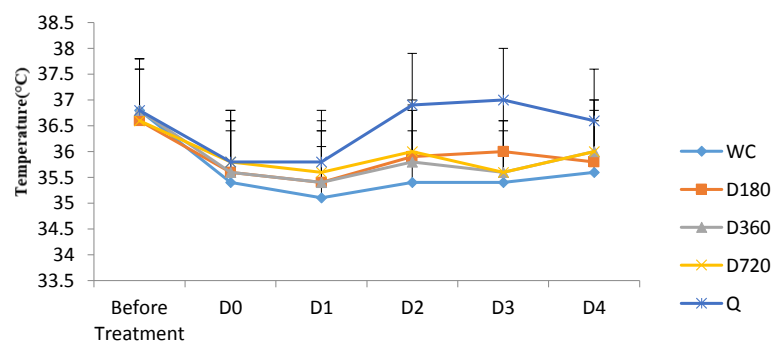

Fig. (2). Variation of temperatures treated with $A$. bipindensis extract. $\mathrm{WC}=$ water control; $\mathrm{Q}=$ Quinine control; $\mathrm{D} 720=720 \mathrm{mg} / \mathrm{kg}$ dose; $\mathrm{D} 360=360 \mathrm{mg} / \mathrm{kg}$ dose; $\mathrm{D} 180=180 \mathrm{mg} / \mathrm{kg}$ dose, $\mathrm{n}=6$.

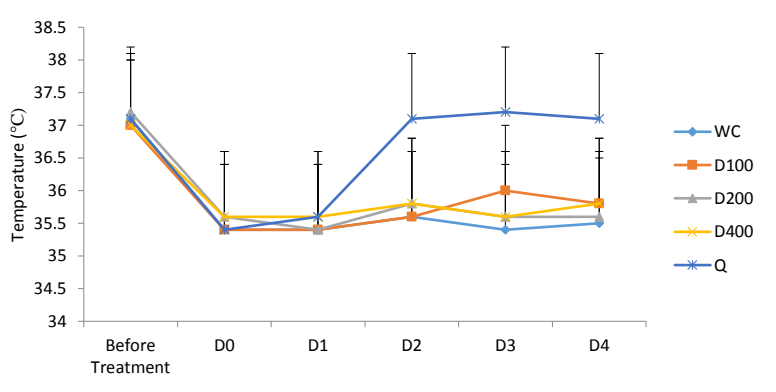

Fig. (3). Temperature variation of animals treated with Senna siamea extract. $\mathrm{WC}=$ water control; $\mathrm{Q}=$ Quinine control; D400 $=400 \mathrm{mg} / \mathrm{kg}$ dose; D200 =200 mg/kg dose; D100 = $100 \mathrm{mg} / \mathrm{kg}$ dose, $\mathrm{n}=6$.

The effect of $A$. bipindensis and $S$. siamea on the weight of the mice was also evaluated. The difference in the body weight of the rats was statistically insignificant. However, the S. siamea treated rats showed less weight gain compared to the control rats.

\subsection{Effects of $A$. bipindensis and $S$. siamea Extracts on Eaematological and Eiochemical Parameters}

Tables ( 4-7) show the effect of extracts on hematological and biochemical parameters. For A. bipindensis we found a statistically significant difference in triglyceride levels between the water control group and the D360 and D720 groups. There is also a significant difference between ALT at D720 compared with other groups. Regarding Senna siamea, no statistically significant differences in the haematological and biochemical parameters between the different groups of animals were observed.

\subsection{Effects of Afzelia bipindensis and Senna siamea Extracts on the Relative Weight of Organs}

Tables 8 and 9 show the effect of extracts of Afzelia bipindensis and Senna siamea on the relative weight (\%) of some organs. The values in the tables represent the averages of the relative weights of each organ as a function of dose; there is no significant difference between groups regardless of the extract. 
Table 4. Haematological parameters after 28 days of oral administration of extracts of $\boldsymbol{A}$. bipindensis.

\begin{tabular}{|c|c|c|c|c|}
\hline Hematological Parameter & Control & Dose 180 mg/kg & Dose 360 mg/kg & Dose 720 mg/kg \\
\hline Leucocytes $\left(10^{3} / \mathrm{mm}^{3}\right)$ & $7.66 \pm 4.66$ & $5.30 \pm 2.34$ & $7.50 \pm 2.96$ & $6.62 \pm 1.10$ \\
\hline Erythrocytes $\left(10^{6} / \mathrm{mm}^{3}\right)$ & $5.06 \pm 3.04$ & $3.80 \pm 1.22$ & $5.42 \pm 0.93$ & $6.32 \pm 0.70$ \\
\hline Hemoglobin $(\mathrm{g} / \mathrm{dl})$ & $10.46 \pm 5.11$ & $8.99 \pm 6.04$ & $10.66 \pm 2.23$ & $10.30 \pm 1.50$ \\
\hline Hematocrit $(\%)$ & $30.92 \pm 15.05$ & $35.77 \pm 10.22$ & $30.90 \pm 6.33$ & $35.15 \pm 6.50$ \\
\hline Platelets $\left(10^{3} / \mathrm{mm}^{3}\right)$ & $229.40 \pm 36.41$ & $233 \pm 42.46$ & $252.70 \pm 34.67$ & $287.32 \pm 56.44$ \\
\hline $\mathrm{MCV}(\mathrm{fl})$ & $87.00 \pm 12.43$ & $78.40 \pm 15.40$ & $90.70 \pm 2.98$ & $82.60 \pm 5.96$ \\
\hline MCHT $(\mathrm{pg})$ & $29.62 \pm 1.17$ & $35.74 \pm 3.84$ & $34.66 \pm 1.44$ & $34.68 \pm 2.56$ \\
\hline MCHC $(\mathrm{g} / \mathrm{dl})$ & $33.98 \pm 1.09$ & $31.45 \pm 0.39$ & $34.06 \pm 0.44$ & $36.39 \pm 0.88$ \\
\hline
\end{tabular}

Hematologic parameters: $M C V$ (mean corpuscular volume), MCHT (mean hemoglobin content), MCHC (mean hemoglobin concentration). The data represent the mean \pm standard deviation for each group of rats $(n=6)$

Table 5. Hematological parameters after 28 days of oral administration of extracts of Senna siamea.

\begin{tabular}{|c|c|c|c|c|}
\hline Hematological Parameter & Control & Dose 100 $\mathbf{~ g} / \mathbf{k g}$ & Dose 200 $\mathbf{~ m g} / \mathbf{k g}$ & Dose 400 mg/kg \\
\hline Leucocytes $\left(10^{3} / \mathrm{mm}^{3}\right)$ & $7.66 \pm 4.66$ & $4.38 \pm 3.46$ & $7.70 \pm 3.93$ & $5.82 \pm 1.20$ \\
\hline Erythrocytes $\left(10^{6} / \mathrm{mm}^{3}\right)$ & $5.06 \pm 3.04$ & $4.83 \pm 1.37$ & $3.95 \pm 0.85$ & $4.44 \pm 0.63$ \\
\hline Hemoglobin $(\mathrm{g} / \mathrm{dl})$ & $10.46 \pm 5.11$ & $9.72 \pm 7.66$ & $11.54 \pm 2.79$ & $11.40 \pm 1.91$ \\
\hline Hematocrit $(\%)$ & $30.92 \pm 15.05$ & $31.76 \pm 12.61$ & $32.88 \pm 8.14$ & $34.10 \pm 5.51$ \\
\hline Platelets $\left(10^{3} / \mathrm{mm}^{3}\right)$ & $229.40 \pm 36.41$ & $220.20 \pm 32.22$ & $242.40 \pm 42.79$ & $247.20 \pm 46.44$ \\
\hline MCV (fl) & $87.00 \pm 12.43$ & $89.40 \pm 9.88$ & $82.80 \pm 2.77$ & $76.80 \pm 7.36$ \\
\hline MCHT (pg) & $29.62 \pm 1.17$ & $24.94 \pm 0.84$ & $27.06 \pm 0.90$ & $25.68 \pm 2.97$ \\
\hline MCHC $(\mathrm{g} / \mathrm{dl})$ & $33.98 \pm 1.09$ & $30.28 \pm 3.24$ & $35.06 \pm 0.29$ & $33.34 \pm 0.73$ \\
\hline
\end{tabular}

Hematologic parameters: $M C V$ (mean corpuscular volume), MCHT (mean hemoglobin content), MCHC (mean hemoglobin concentration). The data represent the mean \pm standard deviation for each group of rats, $(n=6)$.

Table 6. Biochemical parameters in rats after 28 days of oral administration of aqueous extracts of Afzelia bipindensis.

\begin{tabular}{|c|c|c|c|c|}
\hline Biochemical Parameters & Control & Dose 180 mg/kg & Dose 360 mg/kg & Dose 720 mg/ $\mathbf{~ k g}$ \\
\hline AST & $64.00 \pm 5.24$ & $65.22 \pm 17.34$ & $64.32 \pm 18.30$ & $60.26 \pm 10.44$ \\
\hline ALT & $140.85 \pm 17.36$ & $160.93 \pm 12.12$ & $171.38 \pm 16.25$ & $213.58 \pm 20.50^{*}$ \\
\hline Glucose & $63.56 \pm 17.96$ & $78.64 \pm 22.40$ & $64.24 \pm 19.50$ & $80.28 \pm 20.98$ \\
\hline Blood urea nitrogen & $65.02 \pm 11.61$ & $64.44 \pm 14.74$ & $70.22 \pm 16.11$ & $74.90 \pm 10.60$ \\
\hline Total Protein & $90.77 \pm 22.70$ & $87.07 \pm 16.35$ & $88.79 \pm 23.82$ & $85.76 \pm 10.23$ \\
\hline Triglycerides & $229.42 \pm 29.22$ & $289.48 \pm 29.89$ & $123.89 \pm 37.09^{*}$ & $119.38 \pm 22.75^{*}$ \\
\hline Total Cholesterol & $65.67 \pm 10.55$ & $60.31 \pm 14.20$ & $74.23 \pm 17.80$ & $71.89 \pm 11.16$ \\
\hline Creatinine & $0.88 \pm 0.54$ & $2.03 \pm 1.36$ & $0.79 \pm 0.39$ & $0.84 \pm 0.30$ \\
\hline
\end{tabular}

* Significant difference compared to the control group (distilled water) with student $\mathrm{t}$-test $\mathrm{p}<0.05 ; \mathrm{n}=5-6$. The comparison between groups treated was determined using ANOVA and Turkey HSD.

Table 7. Biochemical parameters in rats after 28 days of oral administration of aqueous extracts of Senna siamea.

\begin{tabular}{|c|c|c|c|c|}
\hline Biochemical Parameters & Control & Dose $\mathbf{1 0 0} \mathbf{~ m g} / \mathbf{k g}$ & Dose 200 mg/kg & Dose 400 $\mathbf{~ m g} / \mathbf{k g}$ \\
\hline AST & $64.00 \pm 5.24$ & $57.71 \pm 11.60$ & $54.37 \pm 7.53$ & $50.40 \pm 10.88$ \\
\hline ALT & $140.85 \pm 17.36$ & $174.40 \pm 20.59$ & $168.42 \pm 14.46$ & $170.11 \pm 14.96$ \\
\hline Glucose & $63.56 \pm 17.96$ & $76.93 \pm 24.68$ & $79.20 \pm 18.54$ & $72.27 \pm 16.93$ \\
\hline Blood urea nitrogen & $65.02 \pm 11.61$ & $73.70 \pm 17.34$ & $77.31 \pm 18.21$ & $80.37 \pm 13.68$ \\
\hline Total Protein & $90.77 \pm 22.70$ & $89.04 \pm 12.58$ & $78.59 \pm 23.17$ & $85.71 \pm 27.89$ \\
\hline Triglycerides & $229.42 \pm 29.22$ & $248.48 \pm 39.89$ & $223.89 \pm 24.56$ & $220.21 \pm 18.70$ \\
\hline Total Cholesterol & $65.67 \pm 10.55$ & $78.21 \pm 13.24$ & $74.01 \pm 7.89$ & $74.99 \pm 11.13$ \\
\hline Creatinine & $0.88 \pm 0.54$ & $1.41 \pm 1.88$ & $0.80 \pm 0.37$ & $0.89 \pm 0.32$ \\
\hline
\end{tabular}

*Significant difference compared to the control group (distilled water) with student $\mathrm{t}$-test $\mathrm{p}<0.05 ; \mathrm{n}=5-6$. The comparison between groups treated was determined using ANOVA and Turkey HSD. 
Table 8. Effects of Afzelia bipindensis hydroethanolic extract on the organ to body weight ratio in Percentage.

\begin{tabular}{|c|c|c|c|c|}
\hline Organ & Control & Dose 180 $\mathbf{~ m g} / \mathbf{k g}$ & Dose 360 $\mathbf{~ m g} / \mathbf{k g}$ & Dose 720 mg/kg \\
\hline Heart & $0.47 \pm 0.04$ & $0.42 \pm 0.04$ & $0.41 \pm 0.06$ & $0.36 \pm 0.04$ \\
\hline Liver & $4.10 \pm 0.44$ & $4.02 \pm 0.53$ & $4.33 \pm 0.53$ & $3.69 \pm 0.24$ \\
\hline Lungs & $0.80 \pm 0.10$ & $0.80 \pm 0.14$ & $0.89 \pm 0.25$ & $0.96 \pm 0.18$ \\
\hline Kidney & $0.94 \pm 0.14$ & $0.88 \pm 0.06$ & $0.90 \pm 0.04$ & $0.97 \pm 0.14$ \\
\hline Spleen & $0.61 \pm 0.10$ & $0.62 \pm 0.11$ & $0.52 \pm 0.09$ & $0.60 \pm 0.24$ \\
\hline
\end{tabular}

$\mathrm{D} 720=720 \mathrm{mg} / \mathrm{kg}$ dose; D360=360 mg/kg dose; D180=180 mg/kg dose, $\mathrm{n}=6$.

Table 9. Effects of Senna siamea hydroethanolic extract on the organ to body weight ratio in percentage.

\begin{tabular}{|c|c|c|c|c|}
\hline Organ & Control & Dose 100 $\mathbf{~ m g} / \mathbf{k g}$ & Dose 200 $\mathbf{~ m g} / \mathbf{k g}$ & Dose 400 $\mathbf{~ m g} / \mathbf{k g}$ \\
\hline Heart & $0.47 \pm 0.04$ & $0.44 \pm 0.07$ & $0.43 \pm 0.04$ & $0.38 \pm 0.06$ \\
\hline Liver & $4.10 \pm 0.44$ & $3.77 \pm 0.40$ & $3.51 \pm 0.56$ & $3.74 \pm 0.33$ \\
\hline Lungs & $0.80 \pm 0.10$ & $1.14 \pm 0.51$ & $1.06 \pm 0.23$ & $1.07 \pm 0.36$ \\
\hline Kidney & $0.94 \pm 0.14$ & $0.97 \pm 0.14$ & $0.93 \pm 0.04$ & $0.86 \pm 0.11$ \\
\hline Spleen & $0.61 \pm 0.10$ & $0.57 \pm 0.08$ & $0.53 \pm 0.12$ & $0.56 \pm 0.10$ \\
\hline
\end{tabular}

$\mathrm{D} 100=100 \mathrm{mg} / \mathrm{kg}$ dose; D200=200 $\mathrm{mg} / \mathrm{kg}$ dose; $\mathrm{D} 400=400 \mathrm{mg} / \mathrm{kg}$ dose, $\mathrm{n}=6$

\section{DISCUSSION}

Malaria is a serious disease and its prevalence is increasing across tropical countries. For many decades, traditional medicine has been used in the treatment of many diseases including malaria. This study evaluated the antimalarial effect of Afzelia bipindensis and Senna siamea extracts. Afzelia bipindensis and Senna siamea extracts were found reducing malaria in white BALB/c mice. This study helped us show that hydroethanolic extracts of Afzelia bipindensis and Senna siamea reduce to more than half the parasitemia in murine models. The two plants showed good efficiency (Tables $\mathbf{1}$ and 2) against the Plasmodium berghei.

In fact, the antimalarial activity observed could be attributed to the secondary metabolites present in Afzelia bipindensis and Senna siamea, moreover these plants are a rich source of alkaloid, phenolic compound, and flavonoids which contribute in their antiplasmodial activity [16 - 20].

Phytochemical screening of Senna siamea essential oil equally reveals the presence of pure components such as limonenes [21] with an in vitro antiplasmodial activity against FcB1 Plasmodium falciparum with an $\mathrm{IC}_{50}$ varying between 0.5 and $9.8 \mu \mathrm{g} / \mathrm{ml}$ [22].

According to the review covered and to the limits of our knowledge, few studies have been published on the in vivo antiplasmodial activity of Afzelia bipindensis and Senna siamea.

In this study, all treatments induce a reduction in temperature, the quinine-treated mice promptly increase in body temperature, whereas the other treatments, including the water negative control, stay low. One of the major characteristics of malaria is the presence of a swaying fever, and quinine can thwart the polymerisation of heme from haemoglobin and hinder from here the reproduction of the Plasmodium parasite, thus limiting the liberation of pyrogenic substances.

The acute toxicity evaluation of hydroethanolic extracts of
Afzelia bipindensis and Senna siamea in mice can be helpful for their use in traditional medicine to treat malaria in human. The only modifications observed due to the treatment occurred at the first hours of administration of the extract (a little more than four hours for animals treated with Senna siamea and two hours for those treated with Afzelia bipindensis). The animals were dizzy, but these symptoms were fleeting. No other occurrence and weight loss linked to the treatment were observed. These results suggest that these extracts present fair risks for health in unique doses.

According to the review covered, and to the limits of our knowledge, a few studies were carried out on the sub-acute toxicity of Afzelia bipindensis and Senna siamea. To identify the risks against human health due to repeated intake of extracts, a sub-acute toxicity test was carried out during the repeated oral administration of extracts at 180, 360 and 720 $\mathrm{mg} / \mathrm{kg}$ doses for Afzelia bipindensis and at 100, 200 and 400 $\mathrm{mg} / \mathrm{kg}$ doses for Senna siamea in a period of 28 days. No treatment-linked modification was found in animals during the whole period of the treatment. No significant weight loss was recorded in the animals for the different extracts compared to the controls.

Senna siamea extracts brought no significant modification of biochemical parameters evaluated (glucose, total protein, Blood urea nitrogen, total cholesterol and creatinine) and haematological (Numerations and blood count), same observation for Afzelia bipindensis extract at all doses; meanwhile we noted an increase in AST level for the 720 $\mathrm{mg} / \mathrm{kg}$ dose compared to the control group; this level remained normal for the other doses. We also have an increase in the level of serum triglycerides for doses 360 and $720 \mathrm{mg} / \mathrm{kg}$ compared to the control group; this level remained normal for other doses. An increase in serum AST can signify a cardiac dysfunction, hepatopathies, muscular dystrophia and damage to internal organs.

An autopsy of the animals revealed a general darkening of the liver with the presence of inflammatory nodules in animals 
treated with Afzelia bipindensis at $720 \mathrm{mg} / \mathrm{kg}$ dose and two animals treated with Senna siamea at $200 \mathrm{mg} / \mathrm{kg}$ and 400 $\mathrm{mg} / \mathrm{kg}$ doses respectively compared to the controls. Control of the thoracic cavity revealed the presence of inflammatory nodules of the lung of an animal treated with Afzelia bipindensis at $360 \mathrm{mg} / \mathrm{kg}$ dose and an animal treated with Senna siamea at $200 \mathrm{mg} / \mathrm{kg}$ dose compared to the controls. The inflammatory nodules of the liver and lung observed were similar. If the treatment continues for over a long duration, the nodules will be detected in more animals and will subsequently lead to organs deficit such as necrosis, sclerosis cirrhosis and cancer.

The kidney of an animal treated with Senna siamea at 400 $\mathrm{mg} / \mathrm{kg}$ dose was atrophied. The other organs of the animals presented no distinctive signs compared to the control animals. Nevertheless, we noted no statistically significant difference between the relative weights of all the animals treated compared to the control.

\section{CONCLUSION}

The study showed that extracts of Afzelia bipindensis and Senna siamea significantly reduce plasmodium activity in mice. In addition, extracts of these plants at tested doses showed no health risk, thus supporting the use of these compound in the treatment of malaria. However, studies with other Plasmodium strains (Plasmodium falciparum) are suggested.

\section{ETHICS APPROVAL AND CONSENT TO PARTI- CIPATE}

The study was approved by the Animal Care and Use Committee of the Institute of Medical Research and Medical Plants Studies in Cameroon.

\section{HUMAN AND ANIMAL RIGHTS}

Humans did not participate in this research. All animal research procedures followed were in accordance with the US National Research Council's "Guide for the Care and Use of Laboratory Animals".

\section{CONSENT FOR PUBLICATION}

Not applicable.

\section{AVAILABILITY OF DATA AND MATERIALS}

Not applicable.

\section{FUNDING}

None.

\section{CONFLICT OF INTEREST}

The authors declare no conflict of interest, financial or otherwise.

\section{ACKNOWLEDGEMENTS}

Declared None.

\section{REFERENCES}

[1] WHO. Report on malaria in the world. Summary and key points,. 2014, 2, 2-5.

[2] WHO. Report 2015 on Malaria in the World.Summary and key points, 2014, 2, 2-5.

[3] Bowa, C.N. Lettre d'information éditée par le PNLP. Le « messager » éd du 13 Septembre, 2006. Douala. Cameroun, 2006, 56, 14-17.

[4] Mali, PNLP semaine Africaine de Lutte contre le paludisme, 2010, 6, $10-11$.

[5] WHO. Promoting the role of traditional medicine in the health system: Strategy of the African region; , 2011, 28, pp. 5-8.

[6] Phyo, A.P. Nkhoma S, Stepniewska K, Ashley EA, Nair S, McGready R, Moo CI: Emergence of artemisinin-resistant malaria on the western border of Thailand: A longitudinal study. Lancet, 2012, 14, 69-71.

[7] Donkpegan, A.S.L. Hardy OJ, Lejeune P, Oumorou M, Daïnou K, Doucet J-L. A complex of Afzelia species of African forests of economic and ecological interest (bibliographic synthesis). Biotechnol. Agron. Soc. Environ., 2014, 14-16.

[8] Christiana, K.A.; Gidado, AA.; Bertha, DA.; Zakari, A. Phytochemical screening, proximate and elemental analyses of senna siamea (Lam.) leaves from Kashere metropolis of Gombe State, Nigeria. , 2018, 4, .

[9] Sakulpanich, A.; Gritsanapan, W. Laxative anthraquinone contents in fresh and cooked Senna siamea leaves. Southeast Asian J. Trop. Med. Public Health, 2009, 40(4), 835-839.

[PMID: 19842421]

[10] Zirihi, G. KRA A K M., GUEDE-GUINA F. Évaluation de l'activité antifongique de Microglossa pyrifolia (Lamarck) O.Kantze (Astéracée) « PYMI » Revue de Médecine et pharmacie Afrique, 2003, 17, 11-18.

[11] Harborne, A.J. Phytochemical methods a guide to modern techniques of plant analysis; Springer Science \& Business Media, 1998.

[12] Trager, W.; Jensen, J.B. Human malaria parasites in continuous culture. Science, 1976, 193(4254), 673-675.

[http://dx.doi.org/10.1126/science.781840] [PMID: 781840]

[13] Zucker, J.R.; Campbell, C.C. Malaria. Principales of prevention and treatment. Int. J. Infect. Dis., 1993, 7(3), 547-567.

[14] OCDE. Toxicité orale aiguë - Méthode de la dose prédéterminée. In: Lignes directrice de l'OCDE pour les essais de produits chimiques; , 2001; 1, pp. (4)1-15.

[15] OCDE. Étude de toxicité orale à dose répétée pendant 28 jours sur les rongeurs In: Lignes directrice de l'OCDE pour les essais de produits chimiques; , 2001; pp. 1-14.

[16] Bray, D. Warhurst D., Connolly J., O’Neill M., Phillipson, D. Plants as sources of antimalarial drugs. Part 7. Activity of some species of Meliaceae and their constituent limonoids. Phytother. Res., 1990, 4, 29-35.

[http://dx.doi.org/10.1002/ptr.2650040108]

[17] Abdulah, R.; Suradji, E.W.; Subarnas, A.; Supratman, U.; Sugijanto, M.; Diantini, A.; Lestari, K.; Barliana, M.I.; Kawazu, S.; Koyama, H. Catechin isolated from Garcinia celebica leaves inhibit Plasmodium falciparum growth through the induction of oxidative stress. Pharmacogn. Mag., 2017, 13(Suppl. 2), S301-S305. [http://dx.doi.org/10.4103/pm.pm 571 16] [PMID: 28808396]

[18] Astulla, A.; Zaima, K.; Matsuno, Y.; Hirasawa, Y.; Ekasari, W.; Widyawaruyanti, A.; Zaini, N.C.; Morita, H. Alkaloids from the seeds of Peganum harmala showing antiplasmodial and vasorelaxant activities. J. Nat. Med., 2008, 62(4), 470-472.

[http://dx.doi.org/10.1007/s11418-008-0259-7] [PMID: 18523842]

[19] Ramanandraibe, V.; Grellier, P.; Martin, M-T.; Deville, A.; Joyeau, R.; Ramanitrahasimbola, D.; Mouray, E.; Rasoanaivo, P.; Mambu, L. Antiplasmodial phenolic compounds from Piptadenia pervillei. Planta Med., 2008, 74(4), 417-421. [s].

[http://dx.doi.org/10.1055/s-2008-1034328] [PMID: 18484535]

[20] Murugan, K. Chellasamy P. Antimalarial potential of neem limonoids against plasmodium falciparum. International Journal of Current Medical Sciences, 2013, 3, 6-7.

[21] Afoulous, S.; Hicham, F.; Raoelison, E.; Alexis, V.; Moukarzel, B.; Alexis, V. Helichrysum gymnocephalum essential oil: Chemical composition and cytotoxic, antimalarial and antioxidant activities, attribution of the activity origin by correlations journal of molecules, 2011, 6, 13-14. 
[22] Morita, H.; Oshimi, S.; Hirasawa, Y.; Koyama, K.; Honda, T.; Ekasari, W.; Indrayanto, G.; Zaini, N.C. Cassiarins A and B, novel antiplasmodial alkaloids from Cassia siamea. Org. Lett., 2007, 9(18), 3691-3693.

[http://dx.doi.org/10.1021/ol701623n] [PMID: 17685627]

\section{(C) 2019 Leonel Javeres et al.}

This is an open access article distributed under the terms of the Creative Commons Attribution 4.0 International Public License (CC-BY 4.0), a copy of which is available at: (https://creativecommons.org/licenses/by/4.0/legalcode). This license permits unrestricted use, distribution, and reproduction in any medium, provided the original author and source are credited. 